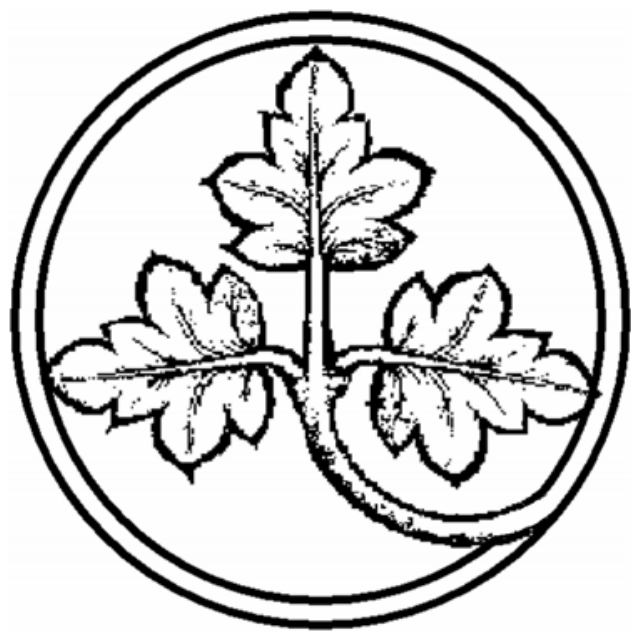

\author{
Preprints of the \\ Max Planck Institute \\ for Research on Collective Goods \\ Bonn \\ 2005/9
}

Second-Best Pollution Taxation and Environmental Quality

Thomas Gaube 


\section{Second-Best Pollution Taxation and Environmental Quality}

Thomas Gaube

April 2005 


\title{
Second-Best Pollution Taxation and Environmental Quality
}

\author{
Thomas Gaube*
}

April 2005

\begin{abstract}
This paper deals with second-best pollution taxation by investigating allocations instead of the corresponding tax rates. Assuming certain restrictions on utility and that the marginal revenue from environmental taxation is positive, it is shown that environmental quality is higher in second best where only distortionary taxes are used to finance public expenditures than in the first-best optimum where lump-sum taxes are available.
\end{abstract}

Keywords: environmental taxation, public goods

JEL-Classification: H21, H41

* Max Planck Institute for Research on Collective Goods, Kurt-Schumacher Str. 10, D53113 Bonn, Germany, phone: +49-228-9141670, fax: +49-228-9141655, e-mail: gaube@mpprdg.mpg.de

I would like to thank Giacomo Corneo, Gabor Gyrfás, two referees, and Don Fullerton (editor) for very helpful comments on an earlier version of this paper which was circulated under the title "Distortionary Taxes Preserve the Environment". The usual disclaimer applies. 


\section{Introduction}

According to the double-dividend hypothesis proposed by Terkla (1984), Lee and Misiolek (1986), and Oates (1993) in a partial equilibrium framework, a pollution tax not only improves the environment (first dividend), but also generates public funds such that the excess burden of other taxes can be reduced (second dividend). Consequently, the second-best tax on dirty activities should exceed the Pigouvian tax which fully internalizes the marginal social damage from pollution. While these two statements are by no means equivalent, most work on the 'double-dividend debate' has dealt with the second claim which is more interesting from a policy perspective. ${ }^{1}$ This claim has been investigated by comparing the first-order conditions which determine the optimal pollution tax in first best and second best respectively. The subsequent analysis complements this literature by asking whether environmental quality is higher in second best than in first best. Hence, the present paper concentrates on the second-best allocation rather than on second-best prices.

In an important contribution, Bovenberg and de Mooij (1994) have criticized the partial equilibrium analyses by investigating a general equilibrium model with wage taxation. They show that the second-best pollution tax can be below the social marginal damage of pollution. Two intuitive arguments for this result have been given. The first one refers to the crowding-out argument of Pigou (1947), namely that the indirect welfare costs of taxation lead to a lower level of public good provision in second best than in first best: "high costs of public funds crowd out not only ordinary public consumption, but also the collective good of the environment" (Bovenberg and de Mooij (1994), p. 1088). According to another argument, the second-best pollution tax is rather low because the wage tax does in itself improve the environment since it reduces employment and labor income of which part is spend on dirty goods (Bovenberg and van der Ploeg (1994), p.

\footnotetext{
${ }^{1}$ The claim concerning the optimal pollution tax means that the additional excess burden created by a revenue neutral environmental tax reform is lower in the presence of other distortionary taxes than with lump-sum taxation. The double-dividend hypothesis, however, means that this additional excess burden is negative, which is a stronger requirement: It implies that the environmental tax reform increases welfare even if the disutility from pollution is ignored (see e.g. Sandmo (2000, Chap. 6) for a discussion). Note that the present paper concentrates on the second-best optimum where the second dividend must be negative by assumption.

${ }^{2}$ See Atkinson and Stern (1974) for a prominent discussion of this topic. An overview of more recent findings can be found in Gaube (2000, 2005).
} 
351). That is, the wage tax implies less pollution than the lump-sum tax in a baseline situation with no pollution levy. Hence, even if the costs of achieving additional reductions in pollution are higher in the presence of wage taxation than in the presence of lump-sum taxation, the optimal amount of environmental quality can still be higher in second best than in first best. ${ }^{3}$ The first argument identifies a low pollution tax with a low level of environmental quality, whereas the second argument explains a low pollution tax by pointing out that the wage tax already serves as an indirect method for preserving the environment. These explanations thus do not clarify whether the entire tax system eventually leads to more or less environmental protection. Moreover, Fullerton (1997) and Schöb (1997) have shown that the optimal pollution tax can exceed the Pigouvian tax if additional expenditures are financed by a consumption tax instead of a wage tax. Since a switch from wage taxation to consumption taxation is just a matter of price normalization, these findings show that one should carefully distinguish between second-best tax rates and the corresponding allocation. ${ }^{4}$

For that reason, I deal with quantities instead of prices. The analysis is framed in terms of the crowding-out hypothesis mentioned above: I ask whether environmental quality and government provision of an ordinary public good is higher or lower in second best than in first best, i.e. whether distortionary taxation leads to more or less provision of collective goods than lump-sum taxation. Assuming certain restrictions on utility, it is shown that providing less of the public good corresponds to providing more environmental quality than in first best (as long as the marginal revenue of environmental taxation is positive). This finding points to a dissimilarity between environmental quality and ordinary public goods: While ordinary public goods are provided by spending public revenue, an increase in environmental quality is achieved by imposing a tax that generates public revenues. If the costs of raising public funds are increased because a lumpsum tax is replaced by distortionary taxes, expenditures on ordinary public goods become more costly, whereas revenues (from environmental protection) become more valuable from a social point of view. Therefore, distortionary taxes provide

\footnotetext{
${ }^{3}$ Second-best environmental quality can thus exceed first-best environmental quality although pollution abatement (i.e. the difference between pollution in the baseline situation and with optimal environmental taxation) should be lower in a second-best world than with lumpsum taxes. See also Bovenberg and Goulder $(1996,2002)$ for a discussion of these arguments.

${ }^{4}$ This point has been emphasized also in Sandmo (2000, Chap. 6.4).
} 
more room for environmental protection than lump-sum taxes. ${ }^{5}$

As noted above, little attention has been given to the analysis of the secondbest allocation. Metcalf (2003) also deals with quantities and asks how an exogenous increase in public good provision affects taxes and the level of environmental quality. It is shown that an increase in public good provision can lead to an increase in environmental quality even though the pollution tax is decreasing. This result also emphasizes the distinction between prices and quantities but leaves open the question whether distortionary taxes affect the optimal level of environmental quality in a different way than lump-sum taxes.

The remainder of this paper is organized as follows. Section 2 presents the model. In Section 3, the link between tax rates and the corresponding quantities is discussed. The crowding-out hypothesis is investigated in Section 4 for a specific class of utility functions, and in Section 5 from a more general perspective. Section 6 concludes.

\section{The Model}

The economy consists of $N$ identical households who consume a clean private commodity $(C)$, a dirty private commodity $(D)$, leisure $(V)$, environmental quality $(E)$, and a public good $(G)$. Each household has an endowment of one unit of leisure and maximizes a strictly quasiconcave utility function $U(C, D, V, E, G)$ which is monotonically increasing in all arguments.

The commodities $C, D$, and $G$ can be produced by means of a linear technology using labor $L:=(1-V)$ as the only input of production. The rates of transformation between $C, D$, and $G$ are normalized to unity. These assumptions imply that the production frontier (expressed in per capita terms) can be written in the form

$$
h(1-V)-C-D-G / N=0,
$$

where the parameter $h$ represents the constant productivity of labor. Environmental quality $E$ is negatively affected by the total amount $N D$ of the dirty

\footnotetext{
${ }^{5}$ In the simplest version of the model analyzed below, environmental quality is higher in second best than in first best if and only if the marginal revenue of the pollution tax is positive. Hence, the finding that distortionary taxes can lead to a higher level of environmental protection does not hinge on the fact that a wage tax reduces labor income relative to lump-sum taxation.
} 
commodity. This assumption is formalized by means of

$$
E=e(N D), \quad e^{\prime}(N D)<0 .
$$

The households take the prices $p_{C}, p_{D}, p_{L}$ of the commodities $C, D, L$ as well as the quantities $G, E$ as given. Each agent maximizes utility $U(C, D, V, E, G)$ with respect to $C, D, V$ subject to the budget constraint

$$
p_{L}(1-V)-p_{C} C-p_{D} D=0
$$

where $p_{L}=h\left(1-t_{L}\right), p_{C}=1+t_{C}$, and $p_{D}=1+t_{D}$. The variables $t_{C}, t_{D}$, and $t_{L}$ stand for the tax rates imposed on private consumption $C, D$, and labor income $h(1-V)$ respectively. ${ }^{6}$

The households' maximization problem leads to the demand functions $C\left(p_{C}, p_{D}, p_{L}, E, G\right), D\left(p_{C}, p_{D}, p_{L}, E, G\right), V\left(p_{C}, p_{D}, p_{L}, E, G\right)$, and the labor supply function $L\left(p_{C}, p_{D}, p_{L}, E, G\right)=1-V\left(p_{C}, p_{D}, p_{L}, E, G\right)$. The indirect utility function is denoted by $W\left(p_{C}, p_{D}, p_{L}, E, G\right)$.

The welfare maximizing government chooses the tax rates $t_{C}, t_{D}, t_{L}$, and the quantity $G$ subject to the budget constraint

$$
t_{C} C+t_{D} D+t_{L} h(1-V)-G / N=0
$$

and the externality constraint (2). Since the households are identical, the optimum can be defined as follows: ${ }^{7}$

$$
\left(t_{C}^{S}, t_{D}^{S}, t_{L}^{S}, G^{S}\right):=\underset{t_{C}, t_{D}, t_{L}, G}{\operatorname{argmax}}\left\{W\left(p_{C}, p_{D}, p_{L}, E, G\right) \mid(2),(3)\right\}
$$

For any solution to (4) there exists a corresponding second-best allocation $\left(C^{S}, D^{S}, V^{S}, E^{S}, G^{S}\right)$ which will be compared with the first-best optimum. The latter is obtained by maximizing the utility function $U(C, D, V, E, G)$ subject to the constraints (1) and (2):

$$
\left(C^{F}, D^{F}, V^{F}, E^{F}, G^{F}\right):=\underset{C, D, V, E, G}{\operatorname{argmax}}\{U(C, D, V, E, G) \mid(1),(2)\} .
$$

The subsequent analysis refers to the question whether $G^{S}$ and $E^{S}$ exceed or fall short of the first-best quantities $G^{F}$ and $E^{F}$.

\footnotetext{
${ }^{6}$ Since consumer prices are defined as the sum of producer prices and tax rates, the producer price of commodity $C$ (or $D$ ) is normalized to unity here. Hence, the gross wage rate is equal to $h$.

${ }^{7}$ Taken together, the budget constraints of the individuals and of the government imply the resource constraint (1). Therefore, this constraint is redundant in the second-best context.
} 


\section{Comparisons}

As noted in the introductory section, previous analyses of the second-best problem (4) have not been concerned with the difference between the quantities $E^{S}$ and $E^{F}$, but have asked whether the second-best tax rate $t_{D}^{S}$ exceeds the Pigouvian $\operatorname{tax} \tau$ which fully internalizes the marginal social damage from pollution. The Pigouvian tax can be determined by means of the first-order conditions corresponding to (5). These conditions imply ${ }^{8}$

$$
\begin{aligned}
& \frac{U_{D}+N e^{\prime} U_{E}}{U_{V}}=\frac{1}{h}, \quad \frac{U_{D}+N e^{\prime} U_{E}}{U_{C}}=1, \\
& \frac{N U_{G}}{U_{V}}=\frac{1}{h}, \quad \frac{N U_{G}}{U_{C}}=1
\end{aligned}
$$

where $U_{K}$ denotes the partial derivative of the utility function $U(\cdot)$ with respect to $K \in\{C, D, V, E, G\}$. The equations in (6) are satisfied if the two tax rates $t_{C}$ and $t_{L}$ are set equal to zero, and $t_{D}$ is set equal to the marginal damage imposed by the dirty commodity $D$, i.e.

$$
t_{D}=\tau:=-\frac{N U_{E} e^{\prime}}{\lambda}
$$

where $\lambda$ denotes the marginal utility of income. ${ }^{9}$ Bovenberg and de Mooij (1994) argue that the second-best tax rate $t_{D}^{S}$ may be lower than the Pigouvian rate $\tau$. More specifically, they show

Proposition 1: [Bovenberg and de Mooij (1994)] Choose the normalization $t_{C}=$ 0 and assume $U(C, D, V, E, G)=\tilde{U}(Q(M(C, D), V), E, G)$ where $M(C, D)$ is homothetic. If $t_{L}^{S}>0$, and if the wage elasticity of labor supply is positive, then $t_{D}^{S}<\tau$.

At first sight, the inequality $t_{D}^{S}<\tau$ indicates less provision of environmental quality in second best than in first-best. However, the examination of a single nominal tax rate does not suffice for a determination of the second-best allocation. This becomes clear by the analysis of Fullerton (1997) and Schöb (1997). They

\footnotetext{
${ }^{8}$ The equations in (6) and (7) are the Samuelson conditions for the commodities E and G respectively. Note that one of these four equations is redundant. For future reference, however, all Samuelson conditions are called into atttention.

${ }^{9}$ With the taxes $t_{C}=t_{L}=0$ we have $\lambda=U_{C}=U_{V} / h, U_{D} / U_{C}=1+t_{D}$, and $U_{D} / U_{V}=$ $\left(1+t_{D}\right) / h$. Hence, (8) is equivalent to $(6)$.
} 
argue that the conclusion $t_{D}^{S}<\tau$ hinges on the chosen normalization $t_{C}=0$. Denoting the government's tax revenue by

$$
R:=t_{C} C+t_{D} D+t_{L} h(1-V)
$$

their findings can be summarized as follows. ${ }^{10}$

Proposition 2: [Fullerton (1997)] Choose the normalization $t_{L}=0$. If $t_{C}^{S}>0$ and

$$
\left(\frac{\partial C}{\partial t_{D}} \frac{\partial R}{\partial t_{C}}-\frac{\partial C}{\partial t_{C}} \frac{\partial R}{\partial t_{D}}\right) /\left(\frac{\partial D}{\partial t_{D}} \frac{\partial R}{\partial t_{C}}-\frac{\partial D}{\partial t_{C}} \frac{\partial R}{\partial t_{D}}\right)<0
$$

then $t_{D}^{S}>\tau$.

It should be noted that the normalizations $t_{C}=0$ and $t_{L}=0$ affect only prices, but not the second-best allocation from (4). Therefore, Propositions 1 and 2 reflect a general feature of tax-models first discussed by Mirrlees (1976): ${ }^{11}$ Any feasible allocation can be implemented by a manifold of tax vectors $\left(t_{C}, t_{D}, t_{L}\right)$ where the sign of each tax rate can be positive or negative depending on the choice of the untaxed good. Fullerton (1997) and Schöb (1997) note that the choice of the untaxed good eventually determines the relative price under consideration. This point can be made explicit by analyzing the allocative consequences of Propositions 1 and 2, i.e by reformulating the two results in terms of the household's marginal rates of substitution. ${ }^{12}$

Remark: (a) If $t_{C}$ is normalized to zero, then $t_{D}^{S}<\tau$ means that

$$
\frac{U_{D}+N e^{\prime} U_{E}}{U_{C}}<1
$$

holds in second best. (b) If $t_{L}$ is normalized to zero, then $t_{D}^{S}>\tau$ means that

$$
\frac{U_{D}+N e^{\prime} U_{E}}{U_{V}}>\frac{1}{h}
$$

holds in second best.

\footnotetext{
${ }^{10}$ Proposition 2 restates Fullerton's result (p. 247). He assumes that a revenue neutral tax reform has opposing effects on the quantities $C$ and $D$. This assumption is formalized here by means of the inequality (9). Schöb (1997) makes a similar point, but refers to the welfare effect of a tax reform at some initial point $t_{D}=t_{C}$ which is not second best.

${ }^{11}$ See p. 331. For an extension of the argument see also Guesnerie (1995), p. 79.

${ }^{12}$ Note that $t_{C}=0$ implies $\lambda=U_{C}$ and $U_{D} / U_{C}=1+t_{D}$, whereas $t_{L}=0$ implies $\lambda=U_{V} / h$ and $U_{D} / U_{V}=\left(1+t_{D}\right) / h$. Using these results, the proof of the remark is straightforward.
} 
This remark points out that Propositions 1 and 2 refer to different marginal rates of substitution or, equivalently, different relative prices. While Proposition 1 shows that the tax differential between the commodities $D$ and $C$ can be lower in second best than in first best, Proposition 2 indicates that the tax differential between commodities the $D$ and $V$ is higher in second best than in first best. ${ }^{13}$ Bovenberg and de Mooij (1997) argue that the ratio $p_{D} / p_{C}$ is more relevant for the evaluation of real-world tax systems than the ratio $p_{D} / p_{L}$ because wage taxation plays a greater role than commodity taxation in practice. However, if one tries to analyze the effect of distortionary taxes on the optimal level of environmental quality, both relative prices (i.e. tax differentials) are of equal importance.

\section{The Crowding-Out Hypothesis Revisited}

The intuitive argument provided in the introductory section points to a dissimilarity between environmental quality and ordinary public goods. It refers to the fact that the provision of ordinary public goods raises public expenditures, while the provision of environmental quality raises public revenue. In order to work out this dissimilarity most clearly, I will restrain the analysis to a simple preference structure described by

$$
U(C, D, V, E, G)=M(C, D)+V+B(G)+H(E)
$$

where the functions $M(C, D), B(G)$, and $H(E)$ are assumed to be strictly concave. For simplicity, I will also assume $e^{\prime \prime}(N D)=0 .{ }^{14}$ Clearly, the assumptions underlying (12) are rather restrictive. The findings of this section will thus be discussed from a more general perspective below in Section 5 .

The utility function (12) has several notable properties. First, it is consistent with the assumptions made in Proposition 1: The assumption of weak separability between $(C, D, V)$ and $(E, G)$ has been strengthened here to additive separability. Moreover, I assume that private utility $Q(M(C, D), V)$ is quasilinear. Note, however, that these assumptions ensure a positive wage elasticity of labor supply (required in Proposition 1) as long as $M(C, D)$ is homogeneous (also required in

\footnotetext{
${ }^{13}$ Clearly, the inequalities (10) and (11) do not depend on the tax normalization. Hence, if (10) holds for the case $t_{C}=0$, it must hold for any other normalization as well. This observation is closely related to the findings of Williams (2001).

${ }^{14}$ It should be noted that the subsequent results still hold as long as $e^{\prime \prime}(\cdot)<0$. In a situation with $e^{\prime \prime}(\cdot)>0$, however, the government's maximization problem may not be concave.
} 
Proposition 1). ${ }^{15}$ Second, the function (12) allows for a straightforward comparison between the quantities $G^{S}$ and $G^{F}$. This feature is due to the quasilinear structure of the utility function and is essential here since earlier contributions on the link between government provision of a public good and distortionary taxation (see Gaube $(2000,2005)$ for an overview) cannot directly be applied to an economy with externalities. ${ }^{16}$ Third, (12) contains the partial equilibrium model analyzed by Terkla (1984), Lee and Misiolek (1986), and Oates (1993) as a special case. This allows us to investigate whether the general equilibrium effects of environmental taxation which have been emphasized by Bovenberg and de Mooij (1994) can be expressed also in terms of the partial equilibrium framework.

Consider now the second-best problem (4) and assume (12). Normalizing $t_{L}$ to zero and substituting (2) into $W\left(p_{C}, p_{D}, p_{L}, E, G\right)$, the first-order conditions with respect to $t_{C}, t_{D}$, and $G$ can be written in the form

$$
\begin{array}{ll}
t_{C}: & -\frac{C}{h}+U_{E} N e^{\prime} \frac{\partial D}{\partial t_{C}}+\mu \frac{\partial R}{\partial t_{C}}=0 \\
t_{D}: & -\frac{D}{h}+U_{E} N e^{\prime} \frac{\partial D}{\partial t_{D}}+\mu \frac{\partial R}{\partial t_{D}}=0 \\
G: & U_{G}-\mu / N=0,
\end{array}
$$

where $\mu$ denotes the Lagrange multiplier associated with the government's budget constraint (3). ${ }^{17}$ The equation (14) can be transformed as follows: First, add and subtract

$$
\frac{\partial R}{\partial t_{D}} \frac{1}{h}=\left(t_{C} \frac{\partial C}{\partial t_{D}}+t_{D} \frac{\partial D}{\partial t_{D}}+D\right) \frac{1}{h}
$$

in (14). This leads to

$$
\frac{t_{C}}{h} \frac{\partial C}{\partial t_{D}}+\frac{t_{D}}{h} \frac{\partial D}{\partial t_{D}}+U_{E} N e^{\prime} \frac{\partial D}{\partial t_{D}}+\left(\mu-\frac{1}{h}\right) \frac{\partial R}{\partial t_{D}}=0
$$

${ }^{15}$ Since this claim can easily be verified no formal proof is provided.

${ }^{16}$ Note that (12) implies neutrality of the public good $G$. Therefore, these preferences are close to a prominent example of second-best public good provision presented by Atkinson and Stern (1974).

${ }^{17}$ The first-order conditions (13) - (15) can easily be derived by employing the following properties: First, note that separability between $(C, D, V)$ and $(E, G)$ implies that the demand functions $C(\cdot)$ and $D(\cdot)$ are independent of $E$ and $G$. Second, Roy's identity, i.e. $\partial W / \partial t_{C}=-C \lambda$ and $\partial W / \partial t_{D}=-D \lambda$ is used. Since the normalization $t_{L}=0$ and the quasilinearity of (12) leads to $\lambda=U_{V} / h=1 / h$, we thus have $\partial W / \partial t_{C}=-C / h$ and $\partial W / \partial t_{D}=-D / h$. 
Because of (6), (8), and $U_{V}=1$, the first-best allocation (5) can be implemented by means of the prices $p_{L}^{F}=h, p_{C}^{F}=1$, and $p_{D}^{F}=1+t_{D}^{F}=1-h N U_{E}^{F} e^{\prime}$. Therefore, the second-best tax rates can be written in the form $t_{C}^{S}:=p_{C}^{S}-1=p_{C}^{S}-p_{C}^{F}$ and

$$
t_{D}^{S}:=p_{D}^{S}-1=\left(p_{D}^{S}-p_{D}^{F}\right)+\left(p_{D}^{F}-1\right)=\left(p_{D}^{S}-p_{D}^{F}\right)-h N U_{E}^{F} e^{\prime} .
$$

Furthermore, due to the quasilinear preferences $(12), D(\cdot)$ and $C(\cdot)$ are Hicksian demand functions. Hence, the symmetry of the Slutzky matrix implies $\partial C / \partial t_{D}=$ $\partial D / \partial t_{C}$. Using these results in (16), one obtains

$$
\frac{p_{C}^{S}-p_{C}^{F}}{h} \frac{\partial D}{\partial t_{C}}+\left[\frac{p_{D}^{S}-p_{D}^{F}}{h}-N e^{\prime}\left(U_{E}^{F}-U_{E}^{S}\right)\right] \frac{\partial D}{\partial t_{D}}+\left(\mu-\frac{1}{h}\right) \frac{\partial R}{\partial t_{D}}=0
$$

where the derivatives $U_{E}^{F}$ and $U_{E}^{S}$ refer to first best and second best respectively.

The equations (13), (15), and (17) will now be used for a comparison between the quantities $G^{S}, G^{F}$ and $E^{S}, E^{F}$. I will start with the simplest version of the model where cross price effects between the two taxed commodities are assumed to be negligible, i.e. $\partial C / \partial t_{D}=\partial D / \partial t_{C}=0$. In a framework without environmental externalities, this assumption leads to the well-known inverse elasticity rule of optimal taxation. Note that cross price effects between the commodities $C$ and $D$ vanish if the second derivative $M_{C D}=M_{D C}:=\partial^{2} M /(\partial D \partial C)$ of the function $M(C, D)$ equals zero. In this case, the utility function (12) represents those preferences which have to be assumed for proper partial equilibrium welfare analysis. Hence, the following result is based on the same assumptions as have implicitly been made in the partial equilibrium models of Terkla (1984), Lee and Misiolek (1986), and Oates (1993).

Proposition 3: Consider the utility function (12) and assume cross price effects between the commodities $C$ and $D$ to be absent. If $t_{C}^{S}>0$, then (a) $G^{S}<G^{F}$ and (b) $E^{S}>E^{F} \Leftrightarrow \partial R / \partial t_{D}>0$.

Proof: (a) Since $M(C, D)$ has been assumed to be strictly concave, we have $\partial C / \partial t_{C}<0$ and $\partial D / \partial t_{D}<0$. With $\partial C / \partial t_{D}=\partial D / \partial t_{C}=0$, the equation (13) reduces to

$$
-\frac{C}{h}+\mu\left(t_{C} \frac{\partial C}{\partial t_{C}}+C\right)=0 .
$$

Because of $\mu>0$ [see the equation (15)] and $t_{C}>0$, this condition implies $\mu>1 / h$. Consider now (7). Since the utility function (12) implies $U_{V}=1$, we have $N U_{G}=1 / h$ in first best. Comparing this condition with (15) (and remembering that $U(\cdot)$ is strictly concave in $G$ ) proves the result. 
(b) I will only prove $\Leftarrow$. The proof of $\Rightarrow$ is analogous: We know from the proof of part (a) that $\partial D / \partial t_{D}<0, \partial D / \partial t_{C}=0$, and $\mu>1 / h$. Hence, as long as $\partial R / \partial t_{D}>0$, the equation (17) implies

$$
\left[\frac{p_{D}^{S}-p_{D}^{F}}{h}-N e^{\prime}\left(U_{E}^{F}-U_{E}^{S}\right)\right] \frac{\partial D}{\partial t_{D}}<0 .
$$

Now assume that the claim is wrong, i.e. that the inequality $E^{S} \leq E^{F}$ holds. This implies $D^{S} \geq D^{F}$. Since $U(\cdot)$ is strictly concave in $E$, and $\partial D / \partial t_{D}=\partial D / \partial p_{D}<$ 0 , it then follows that $\left(U_{E}^{F}-U_{E}^{S}\right)<0$ and $\left(p_{D}^{S}-p_{D}^{F}\right)<0$. Because of $e^{\prime}<0$ and $\partial D / \partial t_{D}<0$, this contradicts (18). Therefore, $E^{S}>E^{F}$.

Proposition 3 shows that the crowding-out hypothesis, i.e. the claim that distortionary taxation reduces the optimal level of public-good provision does indeed hold for the ordinary public good $G$. This result follows from comparing the multiplier $\mu$, i.e. the shadow price of government revenue with the marginal utility of income $1 / h$. In the first-best optimum, the condition $\mu=1 / h$ must hold. As shown in the proof, we have $\mu>1 / h$ in second best if and only if the consumption tax $t_{C}$ is positive. Hence, the welfare cost of increasing public revenue is higher in second best than in first best. Since the optimal amount of $G$ is decreasing in $\mu$ (see the eq. (15)), we thus get $G^{S}<G^{F}$. The inequality $\mu>1 / h$ also means that additional revenue from pollution taxation is more valuable in the case $t_{C}>0$ than with lump-sum taxation. In fact, the pollution tax $t_{D}$ is higher in second best than in first best if and only if $(\mu-1 / h) \partial R / \partial t_{D}$ is positive. Hence, less provision of $G$ in second best is accompanied by more provision of $E$ (relative to first best) if and only if the optimal environmental tax is on the normal side of the Laffer curve for this tax rate. This means that the welfare gain from reducing $E^{S}$ towards the first-best level $E^{F}$ is more than offset by concomitant revenue losses. Note also, that the condition $\partial R / \partial t_{D}>0$ coincides with inequality (9) above, used by Fullerton (1997). Hence, if cross price effects are absent, (9) is necessary and sufficient for $E^{S}>E^{F}$.

It might be worthwhile to point out that the assumptions of Proposition 3 which have implicitly been made in the partial equilibrium literature do not rule out those of Proposition 1. This can be verified by means of the following example where quasilinear preferences (12) are combined with the homogeneous function $M(C, D)=C^{\alpha}+D^{\alpha}, 0<\alpha<1$. This example satisfies all assumptions made in the Propositions 1 and 3 . The claim that the differential between the taxes $t_{D}$ and $t_{C}$ should be lower in second best than in first best can thus be formulated 
within the partial equilibrium model of the earlier literature as well.

So far, I have assumed that cross price effects between the commodities $C$ and $D$ are negligible. In this case, providing less of the public good corresponds to providing more environmental quality than in first best if and only if the marginal revenue $\partial R / \partial t_{D}$ is positive. If, however, cross price effects are significant, the relationship between environmental quality $E$ and tax revenue $R$ does not only depend on the sign of $\partial R / \partial t_{D}$, but also on the derivatives $\partial R / \partial t_{C}$ and $\partial D / \partial t_{C}$. In general, this leads to rather complex conditions for provision of $E$ and $G$. These technicalities can be avoided if the demand function $D\left(p_{C}, p_{D}, p_{L}\right)$ is assumed to be convex in prices $p_{C}$ and $p_{D}$. This assumption contains the linear demand model which has been analyzed for example by Parry (1995) as a special case. ${ }^{18}$

Proposition 4: Consider the utility function (12) and assume that the demand function $D\left(p_{C}, p_{D}, p_{L}\right)$ is convex in prices $p_{C}$ and $p_{D}$. If $G^{S}<G^{F}$ and $\partial R / \partial t_{D}>$ 0 , then $E^{S}>E^{F}$.

Proof: Due to the normalization $t_{L}=0$, we have $p_{L}=h$ in first best and second best. Hence, as long as the function $D\left(p_{C}, p_{D}, p_{L}\right)$ is convex in prices $p_{C}$ and $p_{D}$, the inequality

$$
\left(p_{C}^{S}-p_{C}^{F}\right) \frac{\partial D}{\partial t_{C}}+\left(p_{D}^{S}-p_{D}^{F}\right) \frac{\partial D}{\partial t_{D}} \geq D^{S}-D^{F}
$$

must be satisfied. Using this result in (17), one obtains

$$
\frac{D^{S}-D^{F}}{h}+N\left(U_{E}^{F}-U_{E}^{S}\right) \frac{\partial D}{\partial t_{D}}+\left(\mu-\frac{1}{h}\right) \frac{\partial R}{\partial t_{D}} \leq 0 .
$$

From the equations (15) and (7), we also know that $G^{S}<G^{F} \Leftrightarrow \mu>1 / h$. Applying now the same argument as in the proof of Proposition 3 [see part (b)] proves the result.

Proposition 4 confirms the main result of Proposition 3: Less provision of $G$ in second best is accompanied by more provision of $E$ (relative to first best) if the marginal revenue of the pollution tax is positive. This shows that the intuitive argument provided above is not confined to the partial equilibrium framework, but is relevant also if cross price effects between the commodities $C$ and $D$ are taken into account.

\footnotetext{
${ }^{18}$ Note that convex demand functions do not rule out homothetic preferences which have been assumed by Bovenberg and de Mooij. This can easily be verified by means of the Cobb-Douglas example $M(C, D)=C^{\alpha} D^{\beta}$.
} 


\section{Some Generalization}

Still, the Propositions 3 and 4 rely on rather restrictive assumptions. In the following, I will thus discuss the comparison between the quantities $E^{S}$ and $E^{F}$ from a more general perspective. For this purpose, consider the allocation

$$
\begin{array}{r}
\left(C^{Z}, D^{Z}, V^{Z}, E^{Z}, G^{Z}\right):=\underset{C, D, V, E, G}{\operatorname{argmin}}\{h V+C+D+G / N \mid \\
\left.E=e(N D), \quad U(C, D, V, E, G) \geq U^{S}\right\}
\end{array}
$$

which is constructed by minimizing the amount of resources necessary to achieve the second-best utility level $U^{S}:=U\left(C^{S}, D^{S}, V^{S}, E^{S}, G^{S}\right)$. It can easily be verified that the allocation (19) satisfies the first-best Samuelson conditions (6) and (7) and that it generates the same utility as in second best. Thus, it can be used to identify the "income effect" of moving from first best to second best. In analogy to the Slutzky equation, we can decompose the difference $E^{F}-E^{S}$ by means of

$$
E^{F}-E^{S}=\left(E^{F}-E^{Z}\right)+\left(E^{Z}-E^{S}\right)
$$

where $\left(E^{F}-E^{Z}\right)$ is the income effect and $\left(E^{Z}-E^{S}\right)$ is the substitution effect. The income effect stems from the fact that the second-best allocation lies on a lower indifference surface than the first-best allocation, whereas the substitution effect reflects the fact that at least one of the Samuelson conditions (6) and (7) is violated in second best.

The quasilinear preferences (12) imply $E^{F}=E^{Z}$ and $G^{F}=G^{Z}$, which means that the income effect is zero for environmental quality $E$ and the ordinary public good $G$. Propositions 3 and 4 thus rely on the assumption that an increase in exogenous income has no effect on the Pareto efficient level of environmental quality. Note that environmental quality and consumption of the dirty commodity cannot be increased simultaneously in the present context. In general, the sign of the income effect $E^{F}-E^{Z}$ thus depends on whether the agents care more about the environment or about private consumption of the dirty commodity if their exogenous income is increased. In assuming quasilinear preferences, the previous analysis in Section 4 takes a neutral position regarding this question. Note that empirical evidence concerning the income effect in the presence of distortionary taxation is mixed: Some pollutants decrease with income while others (e.g. $\mathrm{CO}_{2}$ emissions) tend to increase with income (see Arrow et al. (1995) for a discussion). From a general perspective, income neutrality thus seems to be a reasonable 
assumption. It is clear, however, that the conjecture $E^{F}>E^{Z}$ would generate a countervailing effect with respect to the analysis presented above.

Consider next the substitution effect $E^{Z}-E^{S}$, which can be further decomposed along the lines of Metcalf (2003). First, remember from Section 3 that $t_{C}$ and $t_{D}$ are both higher in second best than in first best, even as the differential between $t_{C}$ and $t_{D}$ is smaller. Then, starting from an initial situation with $t_{D}=\tau$ and $t_{C}=0$, an increase in taxation $t_{C}$ and $t_{D}$ leads to a substitution effect away from consumption of produced commodities $C$ and $D$ towards leisure. Second, as the tax differential between $t_{D}$ and $t_{C}$ is reduced, consumers will substitute from $C$ to $D$. The leisure substitution effect thus reduces pollution, whereas the commodity substitution effect increases pollution. Propositions 3 and 4 show that the first effect dominates the second, at least within the framework of partial equilibrium or linear demand, for overall levels of environmental quality.

These findings are in line with Metcalf (2003) who investigates the effect of a marginal increase in exogenous government revenue on environmental quality in second best. Employing the same assumptions as in Proposition 1, he argues that the leisure substitution effect dominates the commodity substitution effect for reasonable parameter values. He also points out that the leisure substitution effect depends on the elasticity of labor supply, whereas the consumption substitution effect depends on the elasticity of substitution between the commodities $C$ and $D$. For an illustration of this line of reasoning, consider the example

$$
U(C, D, V, E, G)=\left(C^{\gamma}+D^{\gamma}\right)^{\alpha / \gamma}+V+B(G)+H(E),
$$

where $0<\alpha<1, \gamma<1$, and $\gamma \neq 0$. In this example, one obtains a constant elasticity of substitution $\sigma:=1 /(1-\gamma)$ and a constant elasticity of labor supply $\epsilon:=\alpha /(1-\alpha)$. Since $M(C, D)$ is homogeneous and $\epsilon>0$, the assumptions of Proposition 1 are fulfilled. As pointed out in Metcalf (2003), these assumptions imply that

$$
p_{D}^{S}=p_{C}^{S}+\left(1+\epsilon-\epsilon p_{C}^{S}\right) \tau \quad \text { and } \quad 1+\epsilon>\epsilon p_{C}^{S}
$$

must hold in second best where $\tau:=-\left(N U_{E} e^{\prime}\right) / \lambda$ is the social marginal damage of the dirty commodity. Using (21), one obtains

$$
p_{D}^{S}-p_{C}^{S}<\tau \text { and } \quad p_{D}^{S}>\tau+1
$$

provided that $p_{C}^{S}>1, \epsilon>0$ and $1>\epsilon \tau$. Note that the first and the second inequality in (22) are equivalent to the inequalities in (10) and (11) respectively. 
They indicate that both prices $p_{C}$ and $p_{D}$ are higher in second best than in first best, but that the price differential $p_{D}-p_{C}$ is lower. A simultaneous increase in $p_{C}$ and $p_{D}$ induces the leisure substitution effect, while a reduction of $p_{D}-p_{C}$ leads to the commodity substitution effect. With respect to the example (20), these effects can be assessed by deriving the demand function

$$
D\left(p_{C}, p_{D}, p_{L}\right)=\left(\frac{\epsilon p_{L}}{(1+\epsilon) p_{D}}\right)^{1+\epsilon}\left(\frac{p_{D}^{\sigma-1}+p_{C}^{\sigma-1}}{p_{C}^{\sigma-1}}\right)^{\frac{\epsilon+1-\sigma}{\sigma-1}} .
$$

Using (21), (22), and (23), it can be shown that the inequalities

$$
\sigma \leq(1+\epsilon)+\frac{1-\epsilon \tau}{\tau} \text { and } \sigma \geq(1+\epsilon)+2 \frac{1-\epsilon \tau}{\tau}(1+\epsilon)
$$

are sufficient for $E^{S}>E^{F}$ and $E^{S}<E^{F}$ respectively. ${ }^{19}$ Metcalf (2003) considers parameter values $\sigma \in\{0.5,1.0,2.0\}$ and $\epsilon \in\{0.15,0.30,0.45\}$ where $\sigma=1$ and $\epsilon=0.30$ is taken as the most plausible case. Using (23), it can easily be demonstrated that the cross price effect $\partial D / \partial p_{C}$ is negative if and only if $\sigma<1+\epsilon$. In this case, the demand for the dirty commodity is decreasing in $t_{D}$ and $t_{C}$ such that environmental quality is higher in second best than in first best. ${ }^{20}$ Therefore, to obtain the opposite result $\left(E^{S}<E^{F}\right)$, a positive cross price effect $\partial D / \partial p_{C}$ (i.e. $\sigma>1+\epsilon)$ is necessary. In this case, the taxes $t_{C}$ and $t_{D}$ have opposing effects on the demand for the dirty commodity $D$. Hence, environmental quality increases with government revenue from taxing dirty consumption and decreases with government revenue from taxing clean consumption. The sign of the total effect depends on the parameters $\sigma, \epsilon$, and the marginal damage $\tau$. Using the second inequality in (24), examples with $E^{S}<E^{F}$ can easily be constructed even if the marginal revenue from environmental taxation is positive. ${ }^{21}$ However, such examples require either a high elasticity of substitution $\sigma$ or a high environmental tax $t_{D}^{S} \cdot{ }^{22}$ Hence, even though the Pigouvian tax increment $p_{D}^{S}-p_{C}^{S}$ is below the marginal damage $\tau$, rather strong assumptions have to be made in order to obtain a lower level of environmental quality in second best than in first best.

\footnotetext{
${ }^{19}$ Since quasilinear preferences imply a zero income effect $E^{F}-E^{Z}$, the difference $E^{F}-E^{S}$ equals the substitution effect $E^{Z}-E^{S}$.

${ }^{20}$ The property $\partial D / \partial p_{C}<0 \Leftrightarrow \sigma<1+\epsilon$ holds generally under the assumptions of Proposition 1. This explains why Metcalf finds a dominating (local) leisure substitution effect for parameters $\sigma=0.5$ and $\sigma=1$.

${ }^{21}$ It can also be shown that the utility function (20) implies $G^{S}<G^{F}$. We thus obtain less provision of both $E$ and $G$ in second best than in first best.

${ }^{22}$ Consider for example the case $t_{D}^{S}<1$ analyzed in Metcalf (2003). Because of $t_{D}^{S}>\tau$, the first inequality in (24) then implies that $E^{S}<E^{F}$ can hold only if $\sigma>2$.
} 


\section{Concluding Remarks}

This paper complements earlier contributions on environmental taxation by investigating allocations instead of prices. I concentrate on the question whether the second-best provision level of a collective good is below or above the corresponding quantity in the first-best optimum. Assuming certain restrictions on utility, it is shown that less provision of ordinary public goods in second best is accompanied by more provision of environmental quality (relative to first best) provided that the marginal revenue of environmental taxation is positive. This finding confirms the idea that the shadow price of the tax revenue from environmental protection is higher in a second-best setting than in a framework where public expenditures can be financed by lump-sum taxation. Of course, the results are restricted to the rather specific assumptions made above. In fact, it is also shown that counterexamples can be constructed with less provision of both $E$ and $G$ in second best even though the marginal revenue $\partial R / \partial t_{D}$ is positive. However, the results make clear that high costs of public funds can serve as a justification for improving environmental quality under reasonable assumptions. Moreover, the single market analysis of Terkla (1984), Lee and Misiolek (1986), and Oates (1993) is shown to be correct as long as it is interpreted with respect to the optimal quantity $E$, and not with respect to the differential between the tax rates $t_{D}$ and $t_{C}$.

Note, however, that the present analysis is based on a model where the environmental quality $E$ can only be enhanced by taxing the consumption of the dirty commodity $N D$. This framework could be generalized along the lines of Bovenberg and van der Ploeg (1994). They assume $E$ to be a function of $N D$ and a public abatement activity $A$, i.e. $E=e(N D, A)$, where $\partial e / \partial(N D)<0$ and $\partial e / \partial A>0$. Taking the expenditures $A$ into account, the government's budget constraint has to be modified such that $t_{C} C+t_{D} D+t_{L} h(1-V)+G+A=0$. In this setting, the government can 'provide' environmental quality in two different ways. First, by taxing $D$ and raising revenue, second by increasing $A$ and raising expenditures. With respect to the second option, environmental quality is analogous to ordinary public consumption. Hence, if we consider the special case $\partial e / \partial(N D)=0$ which means more environmental quality only through abatement, then under-provision of the public good $G$ implies under-provision of $E$ and vice versa. This means that the introduction of abatement activities has a countervailing effect on the findings explored above. Indeed, it is easy to construct 
examples of this generalized model where both under-provision and over-provision may occur depending on the productivity of the abatement technology.

\section{References}

Atkinson, A. B. and N. H. Stern (1974) Pigou, Taxation and Public Goods, Review of Economic Studies 41, No. 1, 119-128.

Arrow, K., B. Bolin, R. Costanza, P. Dasgupta, C. Folke, C. S. Holling, B.O. Jansson, S. Levin, K.-G. Mäler, C. Perrings and D. Pimentel (1995) Economic Growth, Carrying Capacity, and the Environment, Science 268, 520-521.

Bovenberg, A. L. and L. H. Goulder (1996) Optimal Environmental Taxation in the Presence of Other Taxes, American Economic Review 86, 985-1000.

— and - (2002) Environmental Taxation and Regulation, in: Auerbach, A. J. and M. Feldstein (eds.), Handbook of Public Economics Vol. III (Amsterdam: North-Holland), 1471-1545.

Bovenberg, A. L. and R. A. de Mooij (1994) Environmental Levies and Distortionary Taxation, American Economic Review 84, 1085-1089.

— and (1997) Environmental Levies and Distortionary Taxation: Reply, American Economic Review 87, 252-253.

Bovenberg, A. L. and F. van der Ploeg (1994) Environmental Policy, Public Finance and the Labour Market in a Second-best World, Journal of Public Economics 55, 349-390.

Fullerton, D. (1997) Environmental Levies and Distortionary Taxation: Comment, American Economic Review 87, 245-251.

Gaube, T. (2000) When Do Distortionary Taxes Reduce the Optimal Supply of Public Goods?, Journal of Public Economics 76, 151-180.

— (2005) Financing Public Goods with Income Taxation: Provision Rules vs. Provision Level, International Tax and Public Finance (forthcoming).

Guesnerie, R. (1995) A Contribution to the Pure Theory of Taxation (Cambridge: Cambridge University Press).

Lee, D. R. and W. S. Misiolek (1986) Substituting Pollution Taxation for General Taxation: Some Implications for Efficiency in Pollutions Taxation, Journal of Environmental Economics and Management 13, 338-347. 
Metcalf, G. E. (2003) Environmental Levies and Distortionary Taxation: Pigou, Taxation and Pollution, Journal of Public Economics 87, 313-322.

Mirrlees, J. A. (1976) Optimal Tax Theory. A Synthesis, Journal of Public Economics 6, 327-358.

Oates, W. E. (1993) Pollution Charges as a Source of Public Revenues, in: Giersch, Herbert (ed.), Economic Progress and Environmental Concerns (Berlin: Springer), 135-152.

Parry, I. W. H. (1995) Pollution Taxes and Revenue Recycling, Journal of Environmental Economics and Management 29, S64-S77.

Pigou, A. C. (1947) A Study in Public Finance (London: Macmillan).

Sandmo, A. (2000) The Public Economics of the Environment (Oxford: Oxford University Press).

Schöb, R. (1997) Environmental Taxes and Pre-Existing Distortions: The Normalization Trap, International Tax and Public Finance 4, 167-176.

Terkla, D. (1984) The Efficiency Value of Effluent Tax Revenues, Journal of Environmental Economics and Management 11, 107-123.

Williams, R. C., III, (2001) Tax Normalizations, the Marginal Cost of Funds, and Optimal Environmental Taxes, Economics Letters 71, 137-142. 